(Journal of Civil Engineering, Building and Transportation)

Available online http://ojs.uma.ac.id/index.php/jcebt

\title{
Analisa Pemilihan Moda Transportasi Umum Rute Medan-Rantau Prapat dengan Metode Analytic Hierarchy Process
}

\section{Analysis of Public Transport Modes Route Medan-Rantau Prapat with Analytic Hierarchy Process Method}

\author{
Zelvia Zahara* \& Marwan Lubis \\ Program StudiTeknik Sipil, Fakultas Teknik, Universitas Islam Sumatera Utara, Indonesia \\ *Coresponding Email: E-mail : zelviazahara@gmail.com
}

\begin{abstract}
Abstrak
Dalam penelitian ini diteliti faktor atau karakteristik apa saja yang paling berpengaruh dalam pemilihan moda transportasi umum rute Medan-Rantau Prapat, dalam hal ini diperbandingkan antara kereta api dan Bus Chandra. Survey berupa kuesioner yang akan disebar di stasiun kereta api dan Bus Chandra. Hasil survey kemudian diolah dengan menggunakan metode Analytic Hierarchy Process (AHP). Dari analisa data diperoleh faktor yang paling berpengaruh ialah faktor keamanan dengan bobot prioritas sebesar $27 \%$, diikuti oleh kenyamanan $19 \%$, kemudahan $16 \%$, headway $13 \%$, biaya $13 \%$, dan terakhir waktu perjalanan dengan bobot $12 \%$. Hasil bobot prioritas antar kriteria untuk kereta api ialah: Urutan Pertama Faktor Kenyamanan dengan bobot 23\%, diikuti oleh waktu perjalanan 21\%, keamanan 20\%, headway $14 \%$, kemudahan $14 \%$, terakhir biaya dengan bobot $8 \%$. Hasil bobot prioritas antar kriteria untuk Bus Chandra ialah: Urutan Pertama Faktor Biaya dengan bobot 27\%, diikuti oleh, kemudahan dan headway $20 \%$, keamanan $12 \%$, waktu perjalanan $12 \%$, terakhir faktor kenyamanan dengan bobot 9\%. Dan moda terbaik pilihan pelaku perjalanan berdasarkan kriteria yang ada adalah kereta api dengan bobot $62 \%$, sedangkan Bus Chandra kurang diminati dengan bobot 38\%.
\end{abstract}

Kata Kunci : Analytic Hierarchy Process, Kereta Api, Bus

\begin{abstract}
In this case is compared between train and Chandra Bus. The survey is a questionnaire to be spread at Chandra Bus and railway stations. Survey results are then processed using the Analytic Hierarchy Process (AHP) method. From the data analysis, the most favorable factor is financial factor with the priority weight of $27 \%$, followed by the comfort of $19 \%$, comfort $16 \%$, headway $13 \%, 13 \%$ cost, and the last time travel with weight $12 \%$. The weight results between the criteria for trains: First Order Leisure Factor with a weight of 23\%, followed by travel time of $21 \%, 20 \%, 14 \%$ headway, $14 \%$ convenience, the last cost with a weight of 8\%. Priority bus intermediate for Chandra is: First Order Cost Factor with weight of 27\%, followed by ease and headway 20\%, 12\%, travel time 12\%, amount of comfort factor weighing $9 \%$. And the best mode of choice of travelers based on the existing criteria is a train with a weight of $62 \%$, while Chandra Bus less desirable with a weight of $38 \%$.
\end{abstract}

Keywords : Analytic Hierarchy Process, Train, Bus

How to Cite : Zahara, Z, \& Lubis, M. (2017), Analisa Pemilihan Moda Transportasi Umum Rute Medan-Rantau Prapat dengan Metode Analytic Hierarchy Process, JCEBT: Journal of Civil Engineering, Building, and Transportation, 1 (1): 80-86. 


\section{PENDAHULUAN}

Tansportasi antara Medan-Rantau Prapat merupakan salah satu sektor perjalanan tersibuk setiap harinya terutama di akhir pekan atau hari libur. Ada dua moda transportasi umum yang biasa digunakan yaitu Kereta Api dan Bus. Masing-masing moda memiliki karakteristik yang berbeda, salah satunya dari segi biaya. Saat ini bagi pelaku perjalanan yang akan menuju Rantau Prapat dengan menggunakan moda Bus, PT. Chandra menyediakan bus dari Stasiun Amplas dengan biaya yang relatif lebih murah dibandingkan dengan Kereta Api Sri Bilah yang berangkat dari Stasiun KA Medan. Banyak faktor yang mempengaruhi seseorang memilih moda transportasi diantaranya tingkat kenyamanan, waktu perjalanan, keamanan, kemudahan dalam mendapatkan angkutan dan sebagainya. Dalam penelitian ini, akan diteliti faktor apa saja yang mempengaruhi seseorang memilih moda transportasi umum. Dalam hal ini diperbandingkan antara kereta api dan bus, dan seberapa penting faktor tersebut dibandingkan dengan faktor lainnya.

Maksud dan tujuan dari penelitian ini ialah untuk menganalisa moda terbaik yang menjadi pilihan pelaku perjalanan rute Medan-Rantau Prapat berdasarkan kriteria yang ditentukan dalam melakukan perjalanan Medan-Rantau Prapat dan kriteria manakah yang paling berpengaruh dalam pemilihan moda tersebut. Sedangkan tujuannya ialah, untuk mengetahui manakah moda terbaik yang menjadi pilihan pelaku perjalanan rute Medan-Rantau Prapat berdasarkan kriteria yang ditentukan dalam melakukan perjalanan Medan-Rantau Prapat dan untuk mengatahui kriteria manakah yang paling berpengaruh dalam pemilihan moda tersebut.

Penelitian ini menggunakan metode Analytical Hierarchy Process (AHP). Data yang digunakan adalah data primer dan sekunder. Survei dilakukan dengan cara kuisioner. Responden yang dipilih adalah calon penumpang yang berada pada stasiun Kereta Api dan Bus Chandra dengan rute Medan-Rantau Prapat. Faktorfaktor atau parameter kriteria yang ditinjau dalam pemilihan moda angkutan umum ini yaitu: waktu tempuh, biaya, kenyamanan, keamanan, kemudahan, dan headway.

\section{METODE PENELITIAN}

Metodologi Penelitian dilakukan dengan alur berikut :

1. Tahap pertama adalah merumuskan permasalahan.

2. Tahap kedua adalah studi literatur. 
3. Tahap ketiga adalah pengumpulan data primer dan data sekunder.

Data Primer penelitian diperoleh dari jawaban responden secara langsung melalui kuesioner, untuk mendapatkan karakteristik pelaku perjalanan, karakteristik perjalanan dan karakteristik sistem transportasi.

Data Sekunder diperoleh dari dinas terkait maupun dari penelitian lainnya dalam bentuk studi pustaka.

4. Tahap keempat adalah pembahasan/pengolahan data. Data yang diperoleh dari survei dikumpulkan dan diolah menjadi bentuk yang lebih sederhana untuk memudahkan dalam pengerjaan selanjutnya.

5. Tahap kelima adalah analisa data. Dalam hal ini hasil pengolahan data dianalisa model regresinya dilakukan dengan program SPSS. Setelah itu, dihitung nilai probabilitasnya.

6. Tahap keenam adalah kesimpulan dan saran. Pada tahap ini telah diperoleh suatu kesimpulan faktor yang memperngaruhi pemilihan moda transportasi dan nilai probabilitasnya.

\section{HASIL DAN PEMBAHASAN}

\section{Populasi}

Populasi ialah jumlah rata-rata penumpang perhari bus dan kereta api rute Medan-Rantau Prapat dalam satu hari.

a) Bus

Jumlah Penumpang Bus

Chandra/Hari ialah $=27$ orang

b) Kereta Api

Jumlah Penumpang Kereta Api/Hari adalah $=310$ orang

Jumlah Sampel

Rumus Slovin :

$$
n=\frac{\mathrm{N}}{1+\mathrm{N} \cdot e^{2}}
$$

\section{Keterangan}

$\mathrm{N}$ : Jumlah sampel

$\mathrm{N}$ : jumlah populasi

E : Persen tingkat kesalahan (dipakai 10\%)

Perhitungan Jumlah Sampel untuk Bus Chandra

$$
n=\frac{\mathrm{N}}{1+\mathrm{N} \cdot e^{2}}
$$

$$
n=\frac{27}{1+27 \cdot(10 \%)^{2}}=22 \text { orang }
$$

Perhitungan Jumlah Sampel untuk Kereta Api

$$
\begin{aligned}
& n=\frac{\mathrm{N}}{1+\mathrm{N} \cdot e^{2}} \\
& n=\frac{310}{1+310 \cdot(10 \%)^{2}}=76 \text { orang }
\end{aligned}
$$




\section{Pengolahan Data}

\section{$0,111 \times 01,43 \times 0,200)$ (Baris 1)}

Pengolahan data dilakukan dengan menggunakan metoda AHP, berikut contoh $=0,2308$ perhitungan bobot prioritas kriteria terhadap responden 1 .

Menghitung Perkalian baris (z) Prioritas) dengan rumus :

$$
\begin{aligned}
& Z_{i}=\sqrt[n]{\pi a_{i j}} \\
& Z_{i}=\sqrt[n]{a_{i j} x a_{2 j} x a_{3 j} x \ldots x a_{n j}} \\
& Z_{i}=\sqrt{ }(6 \& 1 \times 0,333 \times 0,143 x
\end{aligned}
$$

\begin{tabular}{|c|c|c|c|c|c|c|c|c|}
\hline Kriteria & Biaya & W. Perjalanan & Kemudal & Keamanan & Kenyamanan & Headway & $\begin{array}{l}\text { Perkalian } \\
\text { Baris (z) }\end{array}$ & $\begin{array}{l}\text { Vektor } \\
\text { prioritas } \\
(\mathrm{eVP})\end{array}$ \\
\hline Biaya & 1 & $1 / 3$ & $1 / 7$ & $1 / 9$ & $1 / 7$ & $1 / 5$ & 0,2308 & 0,0285 \\
\hline $\begin{array}{l}\text { W. } \\
\text { Perjalanan }\end{array}$ & 3 & 1 & $1 / 5$ & $1 / 9$ & $1 / 7$ & $1 / 5$ & 0,3521 & 0,0435 \\
\hline
\end{tabular}

$$
\begin{aligned}
& e V P_{1}=\frac{\sqrt[n]{\pi_{j=1}^{n} a_{i j}}}{\sum_{i=1}^{n} \sqrt{\pi_{j=1}^{n} a_{i j}}} \\
& \left.e V P_{1}=\frac{0,2308}{8,0945}=0,029 \text { (baris } 1\right)
\end{aligned}
$$

Tabel 1. Bobot Prioritas Kriteria Responden 1

Tabel 1. Bobot Prioritas Kriteria Responden 1 (Sambungan)

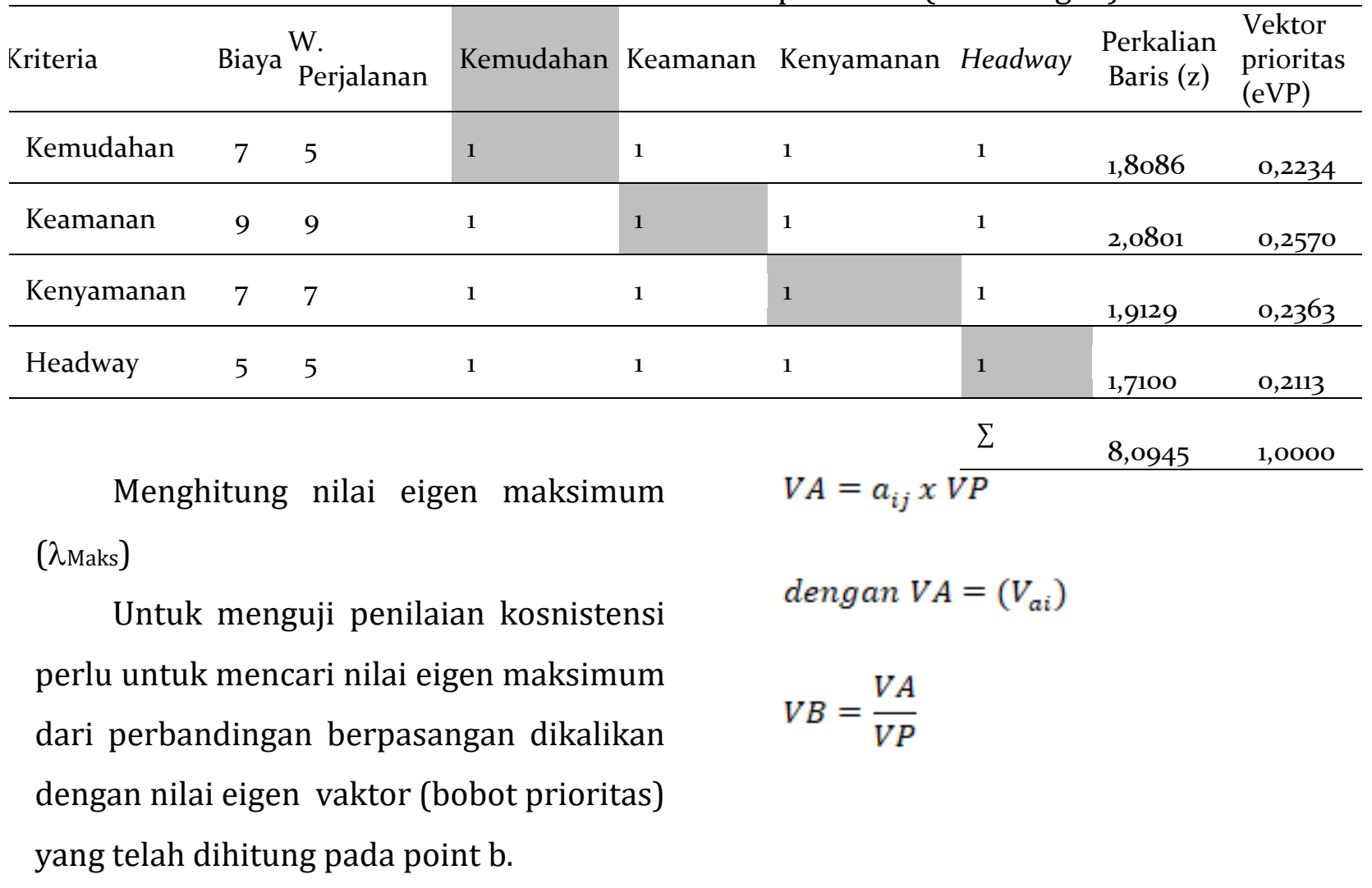


Zelvia Zahara \& Marwan Lubis. Analisa Pemilihan Moda Transportasi Umum Rute Medan-Rantau Prapat

dengan $V B=\left(V_{b i}\right)$

$\lambda$ Maks $=\frac{1}{n} \sum_{i=1}^{n} a_{i j}$

Tabel 2. Eigen Value

\begin{tabular}{|c|c|c|}
\hline$e V P$ & $V A$ & $\begin{array}{l}V B \\
V A / e V P\end{array}$ \\
\hline 0,029 & 0,179 & 6,295 \\
\hline 0,043 & 0,278 & 6,398 \\
\hline 0,223 & 1,345 & 6,020 \\
\hline 0,257 & 1,576 & 6,133 \\
\hline 0,236 & 1,432 & 6,060 \\
\hline 0,211 & 1,288 & 6,097 \\
\hline & $\begin{array}{l}\text { Jumlah } \\
=\frac{1}{6} \times 3\end{array}$ & $\begin{aligned} & 37,003 \\
= & 6,167\end{aligned}$ \\
\hline
\end{tabular}

Indeks Konsistensi (CI)

$C I=\frac{\lambda M a k s-n}{n}$

$C I=\frac{6,167-6}{6}=0,033$
Rasio Konsistensi (CR)

$C R=\frac{C I}{R I}$

$C R=\frac{0,033}{1,24}=0,0269$
$\mathrm{CR}=0,0269 \leq 0,1$

Nilai $\mathrm{CR} \leq 0,01$ maka derajat konsistensi baik, nilai konsistensi baik maka hasil dapat dipergunakan untuk perhitungan bobot prioritas alternatif

\section{Keterangan}

$\mathrm{CR}=$ Consistency Ratio

$\mathrm{CI}=$ Consistensi Index

$\mathrm{RI}=$ Random Indeks (untuk $\mathrm{n}=6, \mathrm{RI}=1,24$ )

Dengan Cara yang sama di analisa pula perhitungan bobot prioritas antar alternatif moda.

Tabel 3. Bobot Prioritas Alternatif (responden 1)

\begin{tabular}{|c|c|c|c|c|c|}
\hline \multirow{3}{*}{ Biaya } & Matriks Kriteria & $\mathrm{KA}$ & Bus Chandra & Perkalian Baris (z) & Bobot Prioritas (evP) \\
\hline & KA & 1 & $1 / 7$ & 0,378 & 0,125 \\
\hline & Bus Chandra & 7 & 1 & 2,6458 & 0,875 \\
\hline \multirow{3}{*}{$\begin{array}{l}\text { Waktu } \\
\text { Perjalanan }\end{array}$} & Matriks Kriteria & KA & Bus Chandra & Perkalian Baris (z) & Bobot prioritas (eVP) \\
\hline & KA & 1 & 1 & 1 & 0,5 \\
\hline & Bus Chandra & 1 & 1 & 1 & 0,5 \\
\hline \multirow{3}{*}{ Kemudahan } & Matriks Kriteria & KA & Bus Chandra & Perkalian Baris (z) & Bobot prioritas (eVP) \\
\hline & $\mathrm{KA}$ & 1 & $1 / 9$ & 0,3333 & 0,1 \\
\hline & Bus Chandra & 9 & 1 & 3 & 0,9 \\
\hline
\end{tabular}

Tabel 2. Bobot Prioritas Alternatif (responden 1) (Sambungan) 


\begin{tabular}{|c|c|c|c|c|c|c|c|}
\hline \multirow{3}{*}{ Keamanan } & \multicolumn{2}{|c|}{ Matriks Kriteria } & \multirow[t]{2}{*}{ KA } & \multicolumn{2}{|c|}{ Bus Chandra } & \multirow{2}{*}{$\begin{array}{c}\text { Perkalian Baris (z) } \\
0,5\end{array}$} & \multirow[t]{2}{*}{$\begin{array}{l}\text { Bobot } \\
\text { prioritas } \\
(\mathrm{eVP}) \\
\end{array}$} \\
\hline & KA & 1 & & 1 & 1 & & \\
\hline & $\begin{array}{l}\text { Bus } \\
\text { Chandra }\end{array}$ & 1 & & 1 & 1 & 0,5 & \\
\hline \multirow{3}{*}{ Kenyamanan } & \multicolumn{2}{|c|}{ Matriks Kriteria } & KA & \multicolumn{2}{|c|}{ Bus Chandra } & Perkalian Baris (z) & $\begin{array}{l}\text { Bobot } \\
\text { prioritas } \\
(\mathrm{eVP})\end{array}$ \\
\hline & KA & 1 & & 9 & 3 & 0,9 & \\
\hline & $\begin{array}{l}\text { Bus } \\
\text { Chandra }\end{array}$ & $1 / 9$ & & 1 & 0,3333 & 0,1 & \\
\hline \multirow{3}{*}{ Headway } & \multicolumn{2}{|c|}{ Matriks Kriteria } & KA & \multicolumn{2}{|c|}{ Bus Chandra } & Perkalian Baris (z) & $\begin{array}{l}\text { Bobot } \\
\text { prioritas } \\
(\mathrm{eVP})\end{array}$ \\
\hline & $\mathrm{KA}$ & 1 & & $1 / 7$ & 0,378 & 0,125 & \\
\hline & $\begin{array}{l}\text { Bus } \\
\text { Chandra }\end{array}$ & 7 & & 1 & 2,6458 & 0,875 & \\
\hline
\end{tabular}

Dari hasil perhitungan di atas dapat dirangkum dalam tabel berikut :

Tabel 3. Bobot Prioritas Kriteria Terhadap Alternatif Moda (Bobot Prioritas Lokal)

\begin{tabular}{l|llllll}
\hline \multirow{2}{*}{ Moda } & \multicolumn{5}{|l}{ Bobot Prioritas Kriteria Terhadap Moda (bobot Prioritas Lokal) } \\
\cline { 2 - 7 } & Biaya & $\begin{array}{l}\text { W. } \\
\text { Perjalanan }\end{array}$ & $\begin{array}{l}\text { Kemudaha } \\
\mathrm{n}\end{array}$ & Keama-nan & Kenyama-nan & Headway \\
\hline KA & 0,125 & 0,500 & 0,100 & 0,500 & 0,900 & 0,125 \\
\hline Bus Chandra & 0,875 & 0,500 & 0,900 & 0,500 & 0,100 & 0,875 \\
\hline
\end{tabular}

\section{Menghitung Bobot Prioritas Global $\left(\begin{array}{llllll}0,125 & 0,500 & 0,100 & 0,500 & 0,900 & 0,125\end{array}\right)$ (Global Priorities) \\ $\left(\begin{array}{llllll}0,875 & 0,500 & 0,900 & 0,500 & 0,100 & 0,875\end{array}\right)$}

Bobot prioritas global adalah $\mathrm{x}$ besarnya ketertarikan responden terhadap moda secara keseluruhan dari seluruh kriteria. Bobot prioritas global didapat dengan mengkalikan matriks bobot

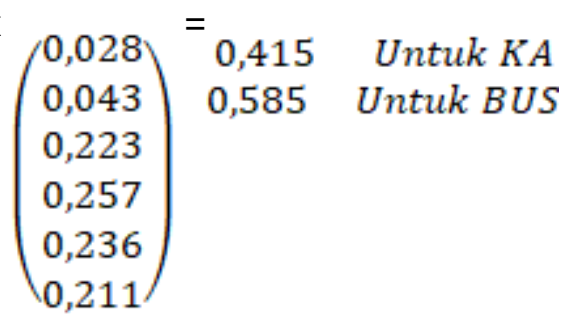
prioritas lokal (Tabel 3) dengan eVP atau bobot prioritas antar kriteria (Tabel 4.4)

Jadi bobot prioritas global responden 1 terhadap moda KA dan bus ialah : KA $42 \%$ dan bus $58 \%$

\section{Rekapitulasi data}

Seluruh hasil perhitungan data terhadap responden dengan nilai $\mathrm{CR} \leq 0,1$ 
di rata-ratakan sehingga diperoleh Rangking bobot prioritas antar kriteria, bobot prioritas antar moda, dan bobot prioritas moda secara global diperoleh.

Tabel 4. Ranking Bobot Prioritas Antar Kriteria

\begin{tabular}{lll}
\hline Kriteria & $\mathrm{eVP}$ & $\mathrm{eVP}(\%)$ \\
\hline Biaya & $\mathbf{0 , 1 2 9}$ & $13 \%$ \\
\hline W. Perjalanan & $\mathbf{0 , 1 2 4}$ & $\mathbf{1 2} \%$ \\
\hline Kemudahan & $\mathbf{0 , 1 5 7}$ & $16 \%$ \\
\hline Keamanan & $\mathbf{0 , 2 7 3}$ & $\mathbf{2 7} \%$ \\
\hline Kenyamanan & $\mathbf{0 , 1 8 7}$ & $19 \%$ \\
\hline Headway & $\mathbf{0 , 1 2 9}$ & $13 \%$ \\
\hline
\end{tabular}

Tabel 5. Bobot Prioritas Global

\begin{tabular}{ll}
\hline Moda & Bobot (100\%) \\
\hline Kereta Api & $62 \%$ \\
\hline Bus & $38 \%$ \\
\hline
\end{tabular}

Tabel 6. Bobot Prioritas Lokal

\begin{tabular}{lll}
\hline \multirow{2}{*}{ Kriteria } & \multicolumn{2}{l}{ Alternatif Moda } \\
\cline { 2 - 3 } & KA & Bus Chandra \\
\hline Biaya & $8 \%$ & $27 \%$ \\
\hline W. Perjalanan & $21 \%$ & $12 \%$ \\
\hline Kemudahan & $14 \%$ & $20 \%$ \\
\hline Keamanan & $20 \%$ & $12 \%$ \\
\hline Kenyamanan & $23 \%$ & $9 \%$ \\
\hline Headway & $14 \%$ & $20 \%$ \\
\hline
\end{tabular}

\section{SIMPULAN}

Moda terbaik yang menjadi pilihan para responden dengan mempertimbangkan kriteria/faktor biaya, keamanan, kenyamanan, kemudahan, headway dan waktu perjalanan adalah moda Kereta Api dengan bobot 62\%. Bus Chandra kurang diminati dibandingkan kereta api dengan bobot prioritas sebesar 38\%. Faktor yang paling berpengaruh dalam pemilihan moda ialah faktor keamanan dengan bobot prioritas sebesar $27 \%$.

\section{DAFTAR PUSTAKA}

Marimin. (2004), Teknik dan Aplikasi Pengambilan Keputusan Kriteria Majemuk. Retrivied juli 5,2015, from http://books.google.co.id/books.Htm

Miro, F. (2011), Pengantar Sistem Transportasi, Penerbit Erlangga, Padang.

Miro, F. (2002), Perencanaan Transportasi untuk Mahasiswa, perencana, dan praktisi, Penerbit Erlangga, Padang.

Morlok, E.K., (1988), Pengantar Teknik dan Perencanaan Transportasi, Penerbit Erlangga, Jakarta, Teknik Mesin, Institut Teknologi Bandung, 2008

Noor, J. (2011). Metode Penelitian Skripsi, Tesis, Disertasi dan Karya Ilmiah, Jakarta: Penerbit Kencana,

Sugiyono, (2009), Metode Penelitian Bisnis, Alfabeta, Jakarta

Rizyak W \& Medis S, Analisa Pemilihan Moda Transportasi Medan-Rantau Prapat dengan Menggunakan Metode Stated Preperence, USU.

Tamin, O.Z. (2000), Perencanaan Pemodelan \& Rekayasa Transportasi, ITB, Bandung.

Tamin, O.Z. (2003), Perencanaan dan Pemodelan Transportasi: contoh soal dan aplikasi, Penerbit ITB, Bandung

Warpani, S. (1990), Merencanakan Sistem Pengangkutan, ITB, Bandung.

http://www.colorado.edu/geography/leyk/geog_5 113/readings/saaty_2008.pdf

https://www.ida.liu.se/ TDDD06/literature/saaty .pdf

http://www.labuhanbatukab.go.id/ 